\title{
Identificação das Expectativas e Dificuldades de Alunos de Graduação no Ensino de Engenharia de Software
}

\author{
Jéssica Costa Mendes ${ }^{1}$, Yandson de Jesus Saraiva Costa ${ }^{1}$, Kastney Frazão ${ }^{3}$, \\ Rodrigo Pereira dos Santos ${ }^{2}$, Davi Viana dos Santos ${ }^{3}$, Luis Jorge Enrique Rivero ${ }^{1,3}$ \\ ${ }^{1}$ Programa de Educação Tutorial de Ciência da Computação (PETComp) \\ Universidade Federal do Maranhão (UFMA) \\ ${ }^{2}$ Programa de Pós-Graduação em Informática (PPGI) \\ Universidade Federal do Estado do Rio de Janeiro (UNIRIO) \\ ${ }^{3}$ Programa de Pós-Graduação em Ciência da Computação (PPGCC) \\ Universidade Federal do Maranhão (UFMA) \\ \{jesscostaj4, yandson.jesus, kastney\}@gmail.com, rps@uniriotec.br, \\ davi.viana@lsdi.ufma.br, luisrivero@nca.ufma.br
}

Abstract. Software Engineering aims to support the development of quality computer systems, reducing production costs and increasing the productivity of practitioners. Understanding the needs of beginning students in this research area is vital in order to propose appropriate teaching methodologies. This paper presents the result of the application of a questionnaire regarding the students' experience of an introductory course on Software Engineering. We captured the expectation of students who have not yet studied software engineering, as well as the vision of students who have already attended, reproving or not. The results of this research allowed identifying possible aspects that may have a positive or negative influence on the learning process.

Resumo. A Engenharia de Software visa apoiar o desenvolvimento de sistemas computacionais de qualidade, reduzindo os custos de produção e aumentando a produtividade dos profissionais. Buscar entender as necessidades dos alunos iniciantes nessa área da computação é vital para propor metodologias adequadas de ensino. Este artigo apresenta o resultado da aplicação de um questionário quanto à experiência dos alunos de uma disciplina introdutória de Engenharia de Software. Foi capturada a expectativa de alunos que ainda não cursaram a disciplina, assim como a visão de alunos que já a cursaram, reprovando ou não. Os resultados desta pesquisa permitiram identificar eventuais aspectos que possam ter influência positiva ou negativa no processo de aprendizado.

\section{Introdução}

A atual revolução tecnológica continua transformando de forma significativa o modo como pensamos e desenvolvemos sistemas de informação (SI). O processo que enfatiza o uso de computadores nas tomadas de decisões é responsável por diversas mudanças de conceitos na sociedade, alterando as formas de produção, de entretenimento, de comunicação, de educação, de comercialização, etc. [Batista 2017]. Atreladas à tais mudanças de preceitos e à criação de novos paradigmas e tendências, a comunidade 
acadêmica tenta se adequar aos resultados desse progresso, objetivando encontrar os melhores meios de preparar os alunos para o futuro.

Visando melhorar a qualidade dos produtos de software e aumentar a produtividade no processo de desenvolvimento, surgiu a Engenharia de Software (ES). A ES trata de aspectos relacionados ao estabelecimento de processos, métodos, técnicas, ferramentas e ambientes de suporte no desenvolvimento de softwares [Sommerville 2011]. No contexto de ensino, assim como o conteúdo abordado é visto com extrema importância, o processo de aprendizado por vezes contempla relevância nos aspectos didáticos e pedagógicos.

Este artigo apresenta o resultado de um questionário aplicado a estudantes do curso de Ciência da Computação da Universidade Federal do Maranhão (UFMA) e tem como objetivo, identificar expectativas e ajudar a mapear eventuais problemas que os alunos possam ter em relação à metodologia aplicada em sala de aula. O questionário é dividido a partir de cinco perfis, considerando a situação dos discentes quanto à disciplina introdutória de ES, sendo alunos que: (1) nunca cursaram a disciplina; (2) no momento de aplicação da pesquisa estavam cursando pela primeira vez; (3) reprovaram e estavam cursando novamente; (4) já haviam cursado e obtiveram aprovação de primeira e (5) foram aprovados após cursarem mais de uma vez.

\section{Ensino de Engenharia de Software}

Engenharia de Software (ES), no contexto acadêmico, é uma disciplina de engenharia cujo foco está em todos os aspectos da produção de software, desde os estágios iniciais da especificação do sistema até sua manutenção, quando o sistema já está sendo usado [Sommerville et al. 2011]. Dada sua importância, é fundamental o sucesso no processo de aprendizagem dos conteúdos da mesma para a boa formação dos estudantes que serão futuros profissionais engenheiros de software.

Comumente, a ES consiste em uma disciplina com diversos conteúdos transmitidos de forma teórica [Andrade et al. 2017], além de aulas expositivas e leituras complementares que abrangem conceitos e fundamentos de ES, e que contemplam a competência prática no desenvolvimento de um pequeno projeto em um curto espaço de tempo [Portela et al. 2016]. Dessa forma, os recém-formados encontram um cenário industrial em que técnicas e métodos aprendidos são pouco aplicados [Santos et al. 2012]. $\mathrm{Ou}$ seja, os profissionais se revestem com práticas ad hoc e/ou aprendidas pela experiência, o que pode afetar negativamente o estabelecimento de práticas de engenharia no processo de desenvolvimento [Von Wangenheim et al. 2009].

Uma parte das mais variadas discussões com enfoque no processo de ensinoaprendizagem da computação têm sido concentrada dentro do Workshop sobre Educação em Computação (WEI), o que o torna para profissionais da área, um relevante fórum brasileiro, promovido pela Sociedade Brasileira de Computação (SBC). Alguns trabalhos têm explorado problemas de aprendizagem em disciplinas de programação e ES [Costa and Bublitz 2013] [Vilarim and Nascimento 2013] e de novas metodologias de ensino [Melo 2013]. Fomentar essas discussões contribui para a obtenção de alternativas de melhorias no ensino e possibilidades inovadoras que aumentem a qualidade dos profissionais brasileiros que estão sendo formados. 


\section{Pesquisa de Opinião}

As pesquisas deste tipo se caracterizam pela interrogação direta das pessoas cujo comportamento se deseja conhecer. Basicamente, procede-se à solicitação de informações a um grupo significativo de pessoas acerca do problema estudado para em seguida, mediante análise quantitativa, obter as conclusões correspondentes dos dados coletados [Gil 2008]. O objetivo do estudo apresentado neste trabalho é identificar as expectativas e as dificuldades de alunos de graduação em relação a disciplina introdutória de Engenharia de Software e com base nas perguntas descritivas apontar problemas de didática que prejudicam o processo de ensino-aprendizagem.

\subsection{Planejamento}

O principal instrumento utilizado para a coleta de dados da pesquisa de opinião consiste em um questionário com perguntas de dois tipos: questões fechadas (QF) e questões abertas (QA).

As questões fechadas foram utilizadas para uniformizar as respostas e sintetizar de forma mais simples a informação pretendida. As mesmas também apoiaram a identificação dos perfis, sendo eles: (i) Alunos que nunca cursaram a disciplina; (ii) Alunos cursando a disciplina pela primeira vez; (iii) Alunos reprovados cursando a disciplina novamente; (iv) Alunos que cursaram a disciplina e foram aprovados de primeira; e (v) Alunos que tiveram que cursar ES mais de uma vez para obter aprovação. As questões abertas permitiram que os participantes descrevessem suas posições de forma mais completa e pudessem expor experiências próprias no processo de ensinoaprendizagem de Engenharia de Software. A princípio, foi elaborado o questionário com a ajuda de um professor-pesquisador doutor em Informática com ênfase em ES e dois alunos, um cursando a disciplina pela primeira vez, e outro que cursou e obteve aprovação de primeira. Foram pensadas questões que extraíssem ao máximo a forma de como a disciplina vem sendo ministrada e as dificuldades que os alunos enfrentam a partir disto.

\subsection{Execução}

A pesquisa de opinião foi aplicada no período 05 a 25 de setembro de 2018 para alunos do curso de Ciência da Computação da Universidade Federal do Maranhão (UFMA), por meio da plataforma Formulário Google, sendo composta tanto por perguntas fechadas (com o objetivo de extrair informações quantitativas) quanto abertas (buscando informações mais qualitativas).

A pesquisa foi divulgada aos alunos mediante portal do grupo de pesquisa em Engenharia de Software e no grupo de e-mail dos discentes do curso de ciência da computação. Além disso, o professor das disciplinas relacionadas com ensino de engenharia de software cedeu tempo da aula para que os alunos pudessem preencher o questionário, indicando que o intuito não era avaliar o aluno nem os professores e que as respostas poderiam ser utilizadas para a melhoria da metodologia de ensino aplicada nas disciplinas lecionadas. Ao todo, 73 estudantes de graduação participaram do questionário, obtendo-se um percentual de respostas de $20,8 \%$ em comparação com o número de alunos ativos no curso em 2018, de acordo com o Departamento de Informática da UFMA. Quanto aos perfis, os 73 discentes estão distribuídos conforme a Figura 1. Não houve nenhum aluno no perfil Alunos reprovados cursando a disciplina novamente. 


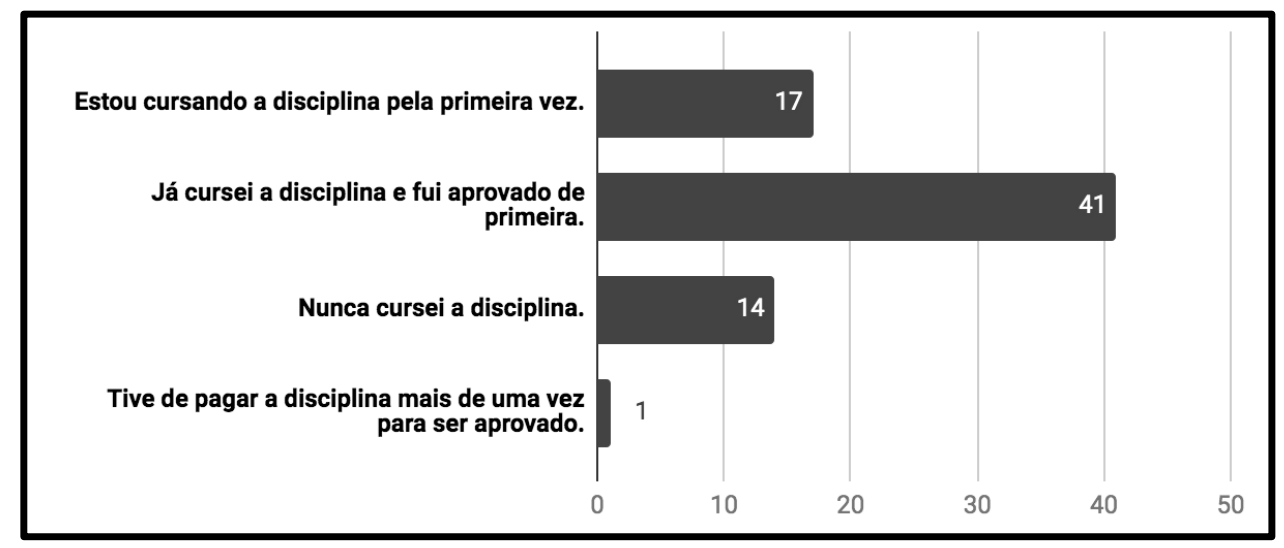

Figura 1. Número de alunos por perfil

\subsection{Procedimento de Análise}

Foram realizadas ao término da aplicação do questionário, análises acerca das respostas fechadas e abertas que foram obtidas. Os dados quantitativos, foram exibidos utilizando estatística descritiva e os dados qualitativos, estatística intuitiva, sendo catalogados utilizando princípios do método Grounded Theory (GT), que trata-se de uma metodologia de pesquisa qualitativa capaz de transformar fatores ontológicos em epistemológicos. Em outras palavras, a GT é dotada de ferramentas que têm como finalidade o desenvolvimento de teorias a partir de dados coletados em uma determinada realidade empírica [Gonçalves 2016].

O GT é composto por três fases ou níveis de codificação, são elas: (1) Codificação aberta (análise e interpretação dos dados); (2) Codificação axial (associação/relacionamento entre as categorias e subcategorias encontradas); (3) Codificação seletiva (avaliação das categorias e identificação se houve ou não um alcance da saturação teórica do tema) [Carossi et al. 2017]. Todas as respostas das QA's foram catalogadas de acordo com a ideia central presente nas respostas, portanto, uma resposta pode conter mais de uma ideia central. Para esta pesquisa, foi utilizada apenas a codificação aberta, com o inteiro de analisar e interpretar os dados.

\section{Resultados da Pesquisa de Opinião}

Após concluída a aplicação da pesquisa de opinião e coleta dos dados, as respostas foram analisadas de acordo com cada um dos perfis. As QA's serão expostas por meio de figuras ao longo das subseções, e os resultados da codificação aberta (descrição dos dados obtidos) serão expostos por meio de gráficos de barra. Já as QF, com os seus respectivos resultados, serão apresentadas por meio de gráficos de pizza.

\subsection{Análise do Perfil: Alunos que Nunca Cursaram a Disciplina}

Dos que responderam o questionário, 14 eram alunos que nunca cursaram a disciplina introdutória de ES. As questões deste primeiro caso foram elaboradas com o intuito de extrair as expectativas dos discentes quanto à disciplina. A partir dos resultados das $\mathrm{QF}$, apresentados nas Figuras 2 e 3, podemos afirmar que alunos que ainda não cursaram a disciplina não conhecem exatamente o que essa área propõe, visto que dos entrevistados, apenas 2 afirmaram saber o que é ES, 10 afirmaram conhecimento mediano e 2 afirmaram não saber (Figura 2). 


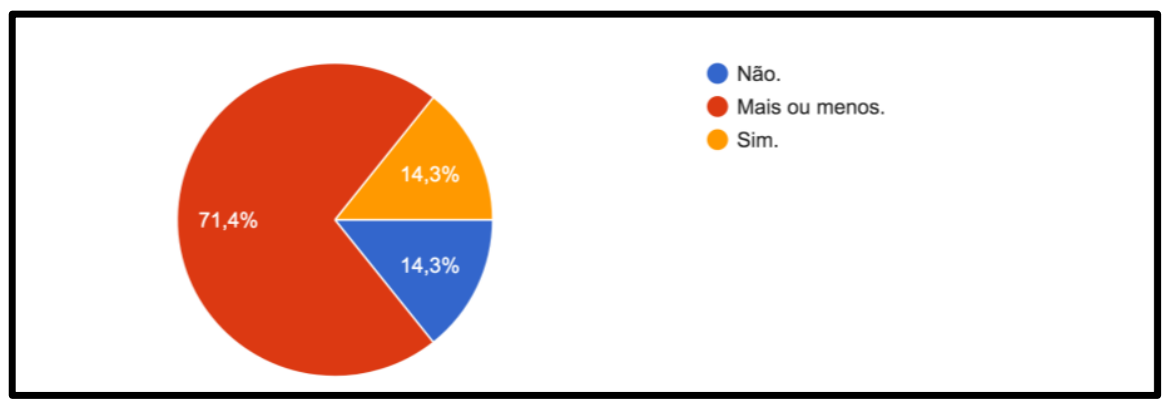

Figura 2. Respostas do Perfil I à pergunta: Você sabe o que é Engenharia de Software?

No entanto, dos 14 alunos, nenhum disse que não tem interesse em aprender Engenharia de Software, e apenas 4 afirmaram ter interesse mediano, o que sugere certo atrativo pela disciplina motivados por curiosidade (Figura 3).

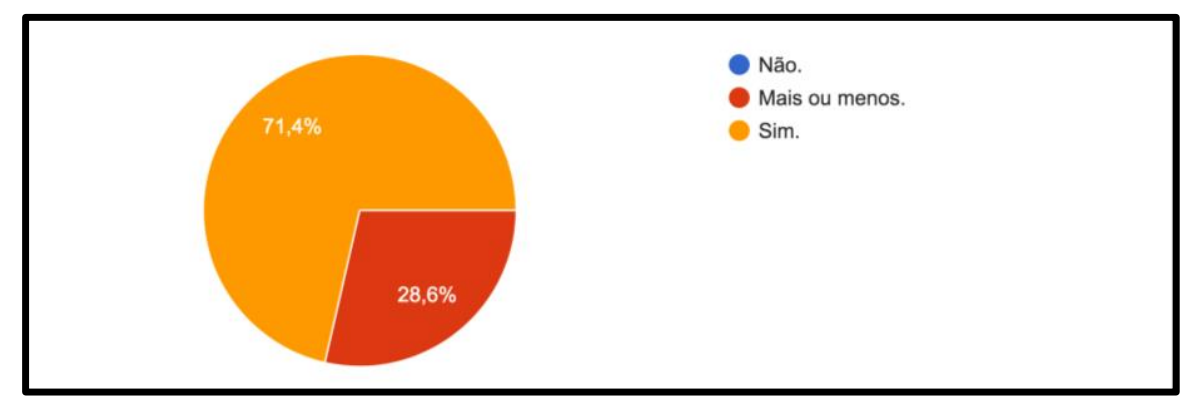

Figura 3. Respostas do Perfil I à pergunta: Você tem vontade de aprender Engenharia de Software?

A Tabela 1 mostra todas as perguntas subjetivas, as quais foram expostas discentes do caso 1. Uma associação entre as respostas dadas às perguntas abertas pode ajudar a capturar as expectativas dos alunos quanto ao desenvolvimento da disciplina, e dar suporte à didática do professor, servindo de referência para o planejamento das aulas a serem aplicadas, despertando assim maior interesse dos alunos.

Tabela 1. QA's do caso 1

\begin{tabular}{|l|l|}
\hline Código & \multicolumn{1}{|c|}{ Descrição } \\
\hline QA 1.1 & $\begin{array}{l}\text { Levando em consideração a pergunta anterior, explique o porquê da sua resposta. } \\
\text { (Referente à pergunta “Você tem vontade de aprender Engenharia de Software?") }\end{array}$ \\
\hline QA 1.2 & Quais são as suas expectativas quanto à disciplina de Engenharia de Software? \\
\hline QA 1.3 & $\begin{array}{l}\text { Como você gostaria que a disciplina de Engenharia de Software fosse aplicada (em } \\
\text { termos de professor, didática, exercícios, etc.)? }\end{array}$ \\
\hline
\end{tabular}

Em relação aos que marcaram ter vontade de aprender ES, em QA 1.1, foram observadas justificativas como: (i) Conceitos e métodos importantes para o mercado de trabalho, (ii) Agregar conhecimento para produção de software, (iii) Identificação com a área e (iv) Ampliar o conhecimento na área. No que diz respeito aos que marcaram a opção "Mais ou menos", em suas respostas foram alegados a falta de identificação e falta de reconhecimento da importância da ES, sendo estas causadas principalmente por opiniões equivocadas a respeito da área, como mostra a Figura 4. 


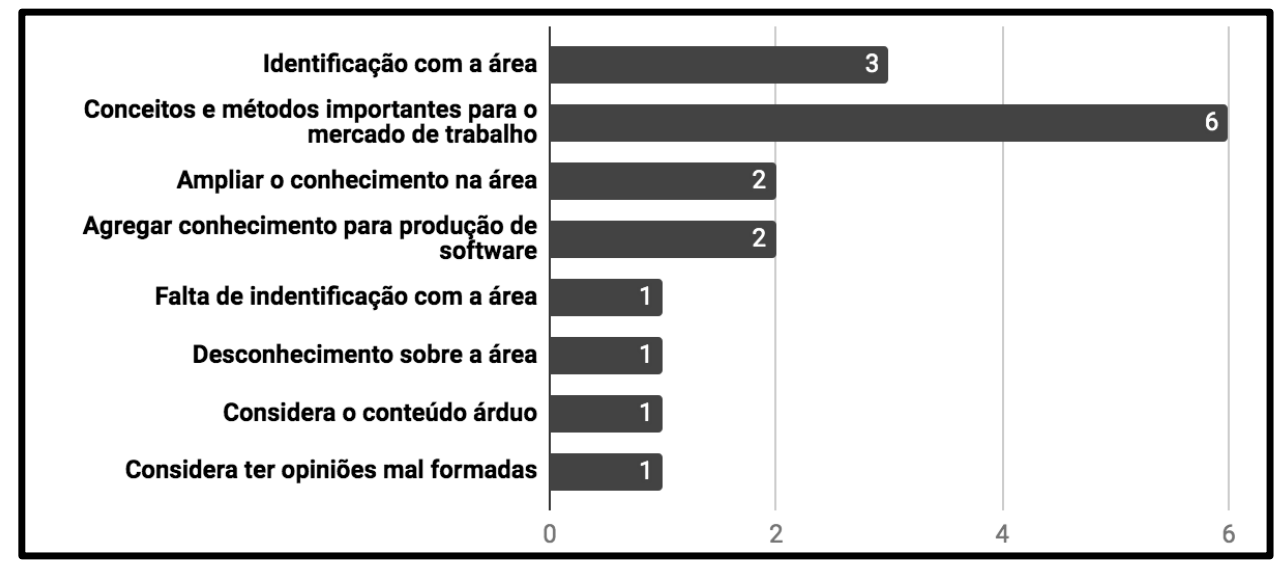

Figura 4. Ideias centrais presentes nas respostas da QA 1.1

A maioria das respostas da QA 1.2 (Figura 5) estão diretamente associadas às citadas pelos discentes na QA 1.1. Analisando-as, foi possível perceber que os alunos esperam identificar-se com a disciplina, entender e colocar em prática os conteúdos aprendidos através de aulas dinamizadas aplicadas em sala de aula, por fim adquirindo aprovação e entendimento da importância da ES no processo de desenvolvimento de projetos computacionais.

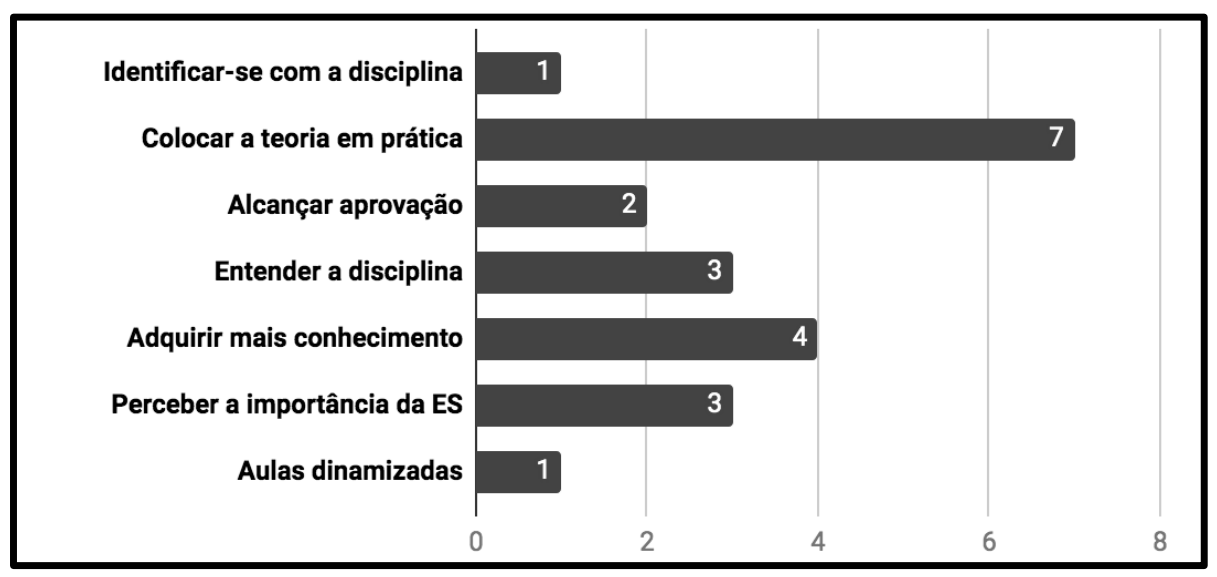

Figura 5. Ideias centrais presentes nas respostas da QA 1.2

A partir das respostas dos alunos em relação às perspectivas quanto à aplicação da disciplina de Engenharia de Software (Figura 6), "Colocar a teoria em prática" obteve maior quantidade de citações. Pois, embora o conhecimento dos conceitos teóricos ser de suma importância para que o aluno consiga desenvolver projetos práticos [Soares 2015], somente este conhecimento não garante que o aluno aprenda de forma efetiva. 


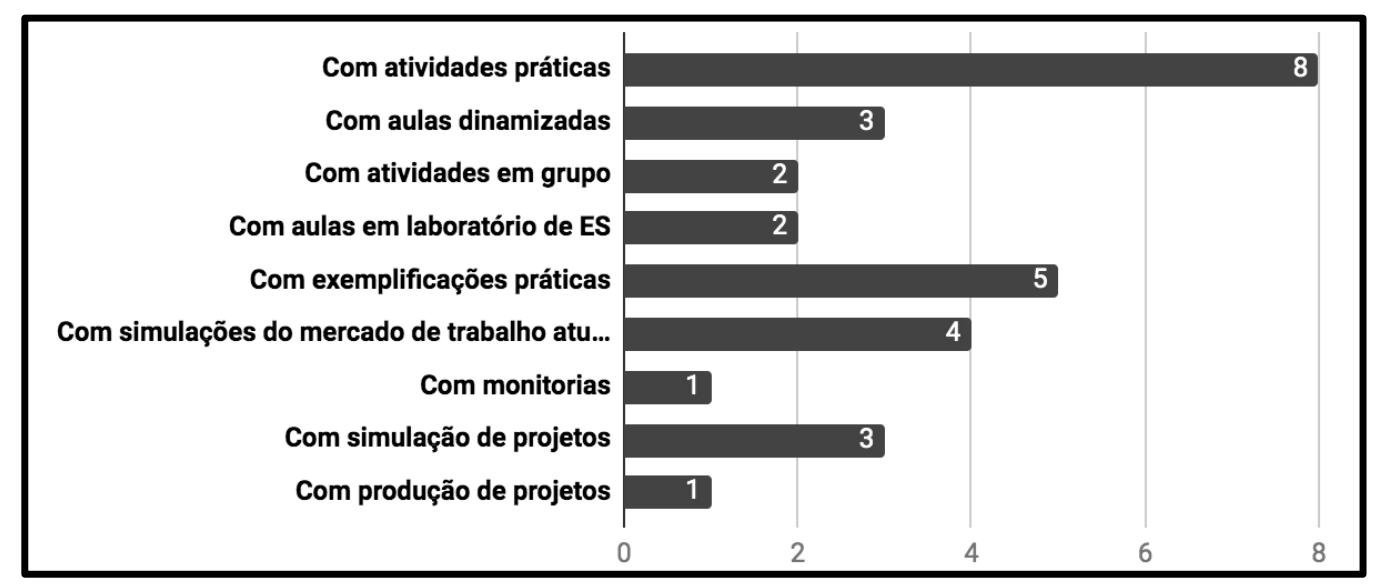

Figura 6. Ideias centrais presentes nas respostas da QA 1.3

\subsection{Análise do Perfil: Alunos Cursando a Disciplina pela Primeira Vez}

Responderam ao questionário, 17 alunos que estavam cursando a disciplina introdutória de ES e não haviam reprovado anteriormente. Todas as perguntas abertas, deste caso, estão apresentadas na Tabela 2. Participantes deste perfil foram expostos à duas perguntas quantitativas, com o intuito de obter o percentual de alunos que iniciam a disciplina considerando saber o que é Engenharia de Software (QF 2.1) e se eles classificam-se com vontade de aprender (QF 2.2). A Figura 7 apresenta os dados coletados e que são relativos à QF 1.2.

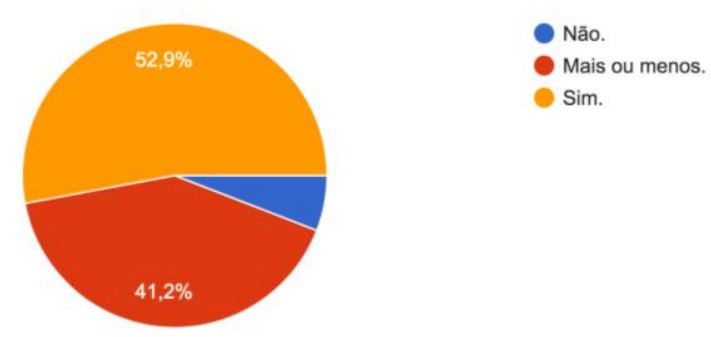

Figura 7. Respostas do Perfil II à pergunta: Você sabe o que é Engenharia de Software I?

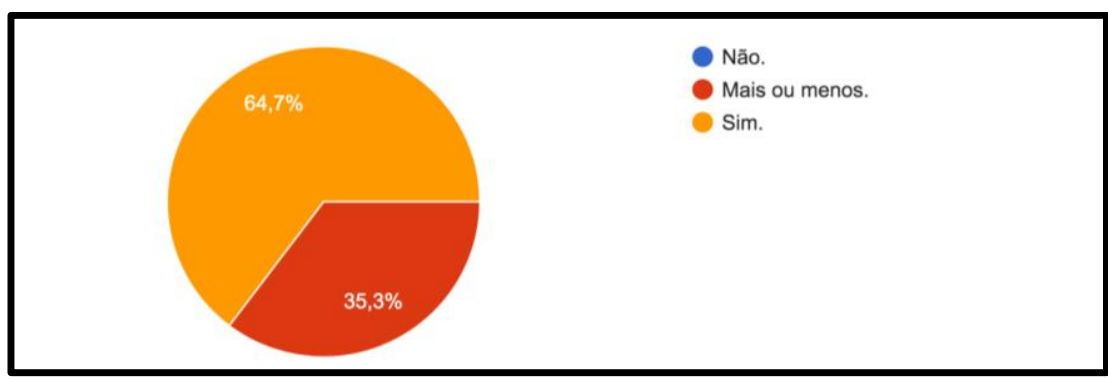

Figura 8. Respostas do Perfil II à pergunta: Você tem vontade de aprender Engenharia de Software I?

Dos alunos cursando a disciplina, 9 deles manifestaram saber o que é ES, 7 marcaram "Mais ou menos" e somente 1 manifestou que não sabe. Ressalta-se que o estudante que afirmou não saber o que é Engenharia de Software, marcou que possui vontade de estudá-la. A combinação de respostas destas duas perguntas iniciais pode fornecer indícios sobre a motivação - ou falta dela - com a disciplina quanto de questões 
pessoais de identificação com a área. A Tabela 2 apresenta todas as QA's respondidas pelos estudantes deste caso.

Tabela 2. QA's do caso 2

\begin{tabular}{|l|l|}
\hline Código & \multicolumn{1}{|c|}{ Descrição } \\
\hline QA 2.1 & $\begin{array}{l}\text { Levando em consideração a pergunta anterior, explique o porquê da sua resposta. } \\
\text { (Referente à pergunta "Você tem vontade de aprender Engenharia de Software?") }\end{array}$ \\
\hline QA 2.2 & Quais são as suas expectativas quanto à disciplina de Engenharia de Software? \\
\hline QA 2.3 & $\begin{array}{l}\text { Como você gostaria que a disciplina de Engenharia de Software fosse aplicada (em } \\
\text { termos de professor, didática, exercícios, etc.)? }\end{array}$ \\
\hline
\end{tabular}

As respostas da QA 2.1 foram catalogadas e classificadas de acordo com os motivos considerados centrais, como mostra a Figura 9. Os discentes que citaram ter vontade de aprender ES, justificaram considerando atributos como: (i) Importância no processo de desenvolvimento de sistemas de qualidade, (ii) Conceitos e métodos importantes no mercado de trabalho e (iii) Versatilidade do conteúdo. No que diz respeito aos que mais marcaram a opção "Mais ou menos", em suas respostas foi alegado gosto pessoal pela disciplina e não reconhecimento de sua importância.

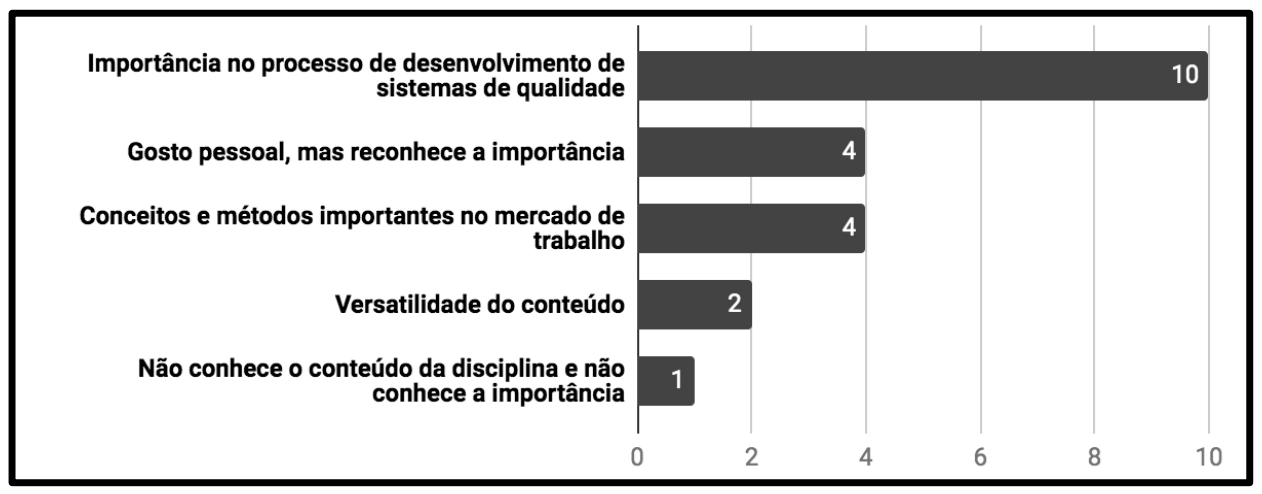

Figura 9. Ideias centrais presentes nas respostas de QA 2.1

Com relação à QA 2.2, os estudantes cursando a disciplina relataram suas expectativas; muitos deles citaram mais de um item como expectativa, e as ideias centrais estão presentes na Figura 10. A QA 2.3 pede aos alunos que discorram acerca de como gostariam que fosse aplicada a disciplina, podendo opinar em relação às características do professor, do material utilizado, da metodologia, etc.

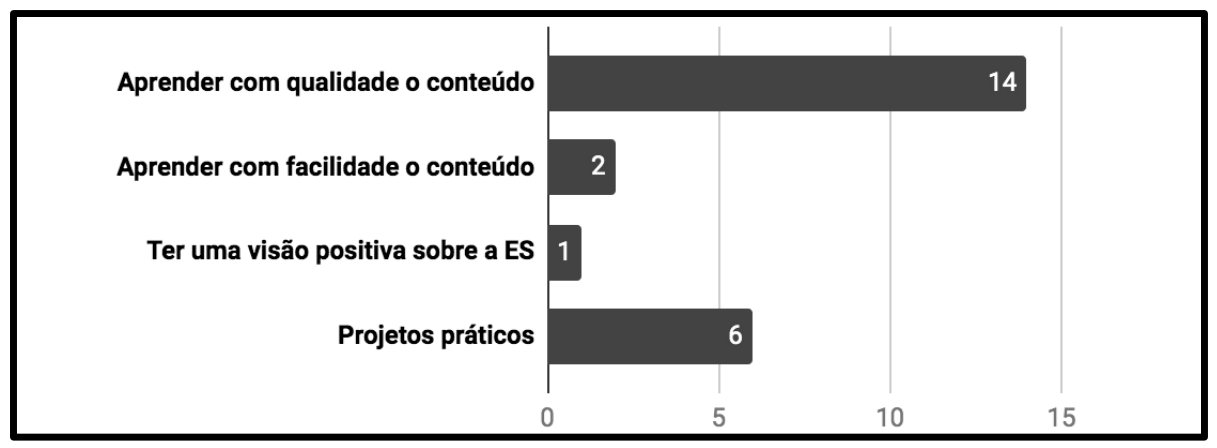

Figura 10. Ideias centrais presentes nas respostas da QA 2.2 
Quando indagados sobre como gostariam que a disciplina ocorresse, os alunos deram sugestões em relação à aplicação de provas e obtenção das notas, além de questões pessoais da aplicação da disciplina pelo professor, conforme mostra a Figura 11.

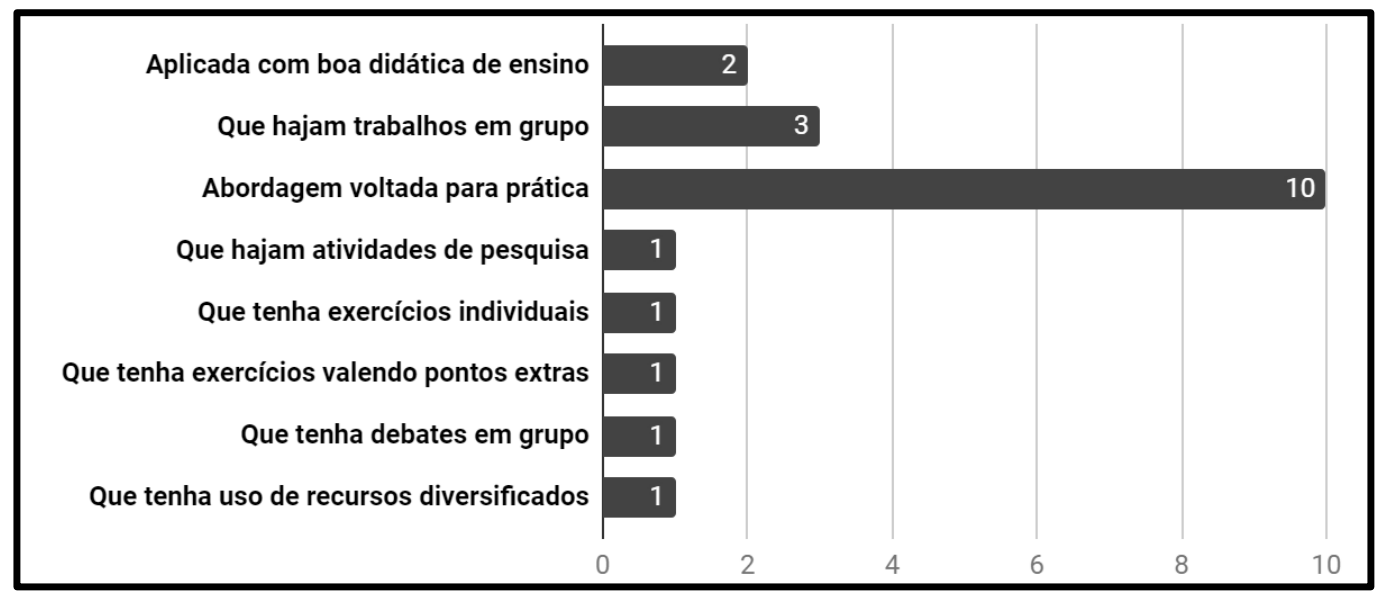

Figura 11. Ideias centrais presentes nas respostas da QA 2.3

\subsection{Análise do Perfil: Alunos que Cursaram a Disciplina e Foram Aprovados de Primeira}

De acordo com os dados colhidos, 41 alunos se encaixaram nesse caso. As questões foram elaboradas com o intuito de buscar entender o que levou à aprovação direta desses alunos, além de descobrir a metodologia utilizada em sala de aula pelo professor, analisando assim a influência da mesma no processo de aprendizado e interesse futuro pela área da ES. As perguntas feitas aos alunos deste caso estão descritas na Tabela 3.

Tabela 3. QA's do caso 3

\begin{tabular}{|l|l|}
\hline Código & \multicolumn{1}{|c|}{ Descrição } \\
\hline QA 3.1 & $\begin{array}{l}\text { Com que professor você cursou a disciplina de Engenharia de Software? (Fique } \\
\text { tranquilo, estes dados são apenas para entender que tipo de metodologia permite } \\
\text { facilitar o aprendizado do aluno - o seu professor não está sendo avaliado aqui e sim } \\
\text { a metodologia de ensino) }\end{array}$ \\
\hline QA 3.2 & $\begin{array}{l}\text { Como foi a disciplina de Engenharia de Software? (Descreva as suas dificuldades, } \\
\text { o que foi fácil, como foram os trabalhos, método de ensino, atividades, etc.) }\end{array}$ \\
\hline QA 3.3 & Quais módulos você sentiu mais dificuldade em aprender durante a disciplina? \\
\hline QA 3.4 & $\begin{array}{l}\text { Você tem vontade de aprender novos assuntos relacionados com Engenharia de } \\
\text { Software? }\end{array}$ \\
\hline QA 3.5 & $\begin{array}{l}\text { Que sugestão você daria ao seu professor para o melhor aproveitamento da disciplina } \\
\text { de Engenharia de Software (em termos de didática, exercícios, etc.)? }\end{array}$ \\
\hline
\end{tabular}

A primeira pergunta feita aos alunos que já cursaram a disciplina e foram aprovados de primeira diz respeito ao professor que aplicou a mesma. Com isso, foram citados 5 professores, nomeados na Figura 12 como A, B, C, D e E, preservando a identidade. Este questionamento foi feito para ajudar no processo de análise das respostas dadas pelos alunos, sendo possível assim haver uma comparação das opiniões de diferentes alunos que tiveram aula com o mesmo professor. 


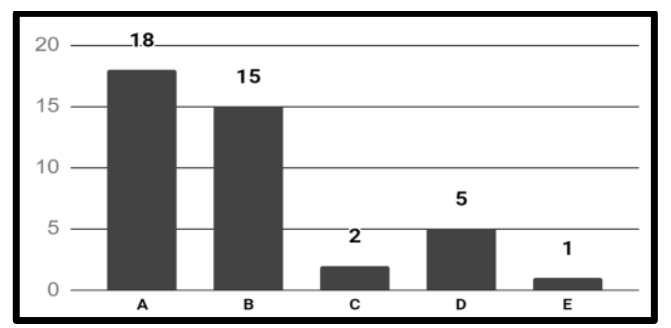

Figura 12. Número de vezes que os professores de ES foram citados no questionário

A segunda questão tem como objetivo ser um espaço em que os discentes possam relatar as dificuldades encontradas durante o processo de aprendizagem na disciplina, possibilitando expor ainda qual foi e como foi a metodologia empregada pelo professor, e desta forma, descrever se a mesma teve influência positiva ou negativa no desenvolvimento do conteúdo e do aluno.

As dificuldades apontadas pelos alunos estão relacionadas com a didática utilizada pelos professores. Na maioria das respostas foi citada como principal dificuldade, entender os conteúdos, por serem inicialmente cansativos demais; além da aplicabilidade do mesmo, o que interferia na transição do conteúdo teórico para a prática. Isso foi percebido pelos alunos durante trabalhos práticos.

As metodologias utilizadas pela maioria dos docentes eram voltadas para aulas, exercícios, trabalhos e avaliações; porém, muitas das vezes os conteúdos eram passados de forma desinteressante, como muito citado, com apenas utilização de slides. Isso implicou, segundo relatos, na perda de interesse pelas aulas ao decorrer da disciplina. Por fim, essa situação faz com que muitos alunos criem opiniões desinformadas sobre a importância da ES durante o processo de desenvolvimento de um projeto. Todas as metodologias bem avaliadas pelos alunos, estão ligadas diretamente a trabalhos e exemplos práticos do mundo real.

A Figura 13 mostra os conteúdos que foram citados pelos alunos como os de maiores dificuldades no processo aprendizado, sendo Requisitos de Software, Metodologias de Desenvolvimento de Software e Manutenção de Software os três com maior número de citações. As justificativas dadas em relação às dificuldades encontradas nesses conteúdos, estão relacionadas à maneira em que foi repassado e explicado em sala de aula, consistindo em uma maneira muito rápida e genérica. Contudo, muitos alunos ainda sentiram-se interessados a seguir e aprender mais sobre a Engenharia de Software, o que mostra que houve a percepção da importância da mesma (Figura 14).

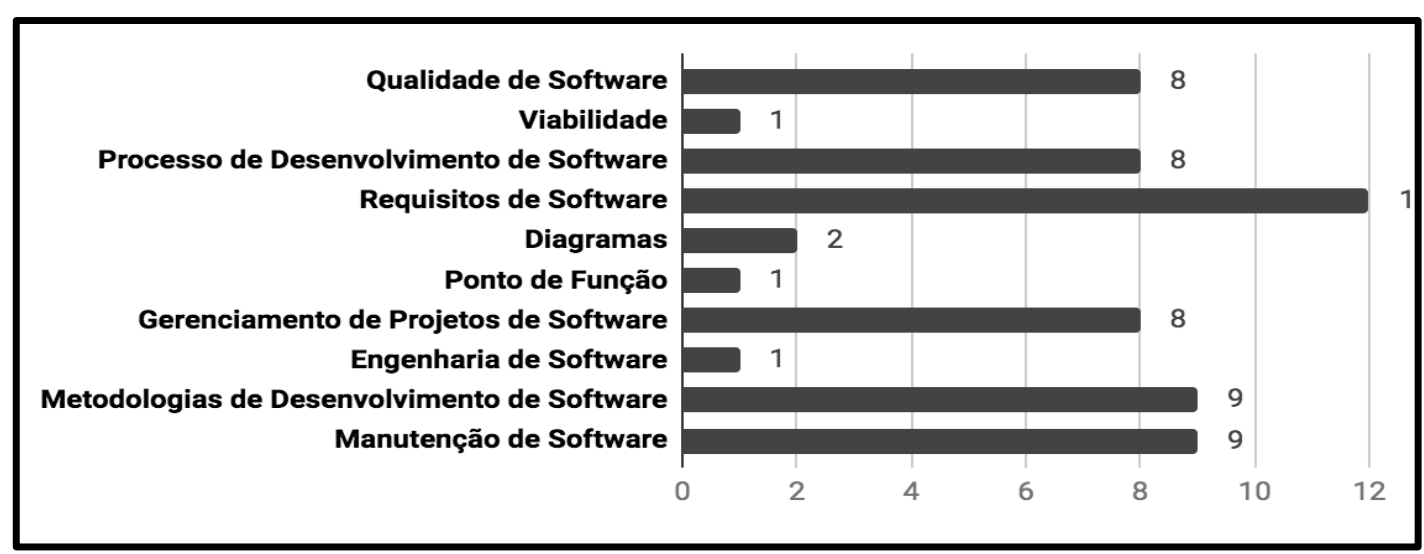

Figura 13. Conteúdos de ES em que os alunos tiveram mais dificuldades 


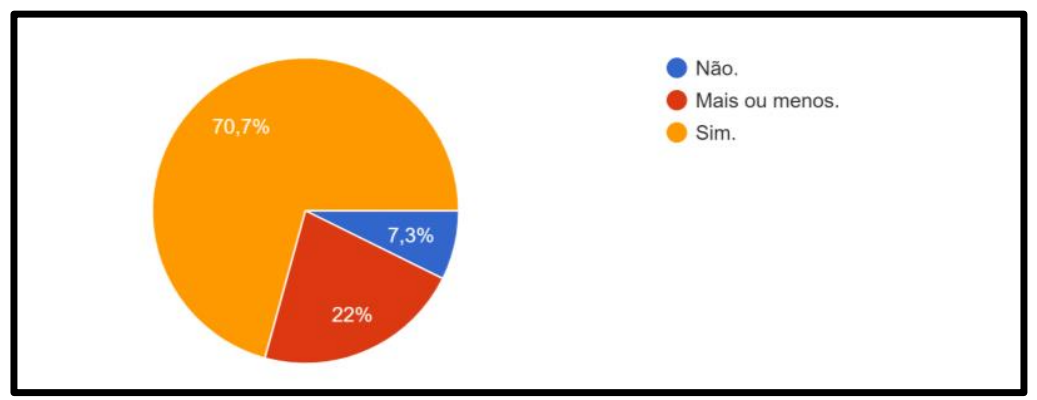

Figura 14. Você tem vontade de aprender novos assuntos relacionados à ES?

Como solução para as dificuldades apresentadas anteriormente, foi perguntado aos alunos quais sugestões eles dariam aos professores para o melhor aproveitamento da disciplina de ES, e os principais pontos citados foram os seguintes: a apresentação de exemplos práticos, como as dificuldades encontradas por profissionais na aplicação das técnicas aprendidas, simulações de projetos, exemplificações e atividades que os levem ao mundo real. Segundo os alunos, estes são apelos que se fossem atendidos despertaria muito mais o interesse deles, tornando a visão em relação aos conteúdos teóricos, que são sim de suma importância, em algo que realmente se faz necessário e útil ao profissional.

\subsection{Análise do Perfil: Alunos que Cursaram Mais de uma Vez para Obter Aprovação}

Somente 1 discente com este perfil participou do questionário. Neste caso, as perguntas têm como objetivo extrair lições de aprendizado, dificuldades no decorrer da disciplina e relatos se a reprovação impactou na motivação em cursar matérias relacionadas à Engenharia de Software. Considerando a amostra pequena de participantes, nesta seção será apresentada as citações que tal discente deu como respostas às QA's (ver Tabela 4) deste caso.

Tabela 4. QA's do caso 4

\begin{tabular}{|c|l|}
\hline Cód. & \multicolumn{1}{|c|}{ Descrição } \\
\hline $\begin{array}{c}\text { QA } \\
4.1\end{array}$ & $\begin{array}{l}\text { Com que professor você reprovou na disciplina de Engenharia de Software? (Fique } \\
\text { tranquilo, estes dados são apenas para entender que tipo de metodologia permite } \\
\text { facilitar o aprendizado do aluno - o seu professor não está sendo avaliado aqui e sim a } \\
\text { metodologia de ensino) }\end{array}$ \\
\hline $\begin{array}{c}\text { QA } \\
4.2\end{array}$ & $\begin{array}{l}\text { Por que você acha que reprovou da primeira vez que cursou a disciplina de Engenharia } \\
\text { de Software? (Descreva suas dificuldades com os trabalhos, método de ensino, } \\
\text { problemas pessoais, etc.) }\end{array}$ \\
\hline QA & $\begin{array}{l}\text { O que você mudaria da primeira vez que cursou a disciplina de Engenharia de Software } \\
\text { para ter um melhor aproveitamento (em termos de didática, exercícios, etc.)? }\end{array}$ \\
\hline QA & $\begin{array}{l}\text { Com que professor você aprovou na disciplina de Engenharia de Software? (Fique } \\
\text { tranquilo, estes dados são apenas para entender que tipo de metodologia permite } \\
\text { facilitar o aprendizado do aluno - o seu professor não está sendo avaliado aqui e sim a } \\
\text { metodologia de ensino) }\end{array}$ \\
\hline QA & $\begin{array}{l}\text { Como foi a disciplina de Engenharia de Software quando você foi aprovado? (Descreva } \\
\text { as suas dificuldades, o que foi fácil, como foram os trabalhos, método de ensino, } \\
\text { atividades, etc.) }\end{array}$ \\
\hline 4.5
\end{tabular}


QA Que sugestão você daria ao professor com quem aprovou para o melhor aproveitamento

4.6 da disciplina de Engenharia de Software (em termos de didática, exercícios, etc.)?

O discente em questão, cursou as duas referidas vezes com o professor B. Além disso, o mesmo marcou no questionário os tópicos de Processo de Desenvolvimento de Software e Metodologias de Desenvolvimento de Software como conteúdos nos que obteve maior dificuldade em aprender durante a disciplina. A resposta que ele deu à QA 4.2 corresponde à uma descrição de como era ministrada a disciplina e como isso afetou sua motivação:

"O jeito em que a disciplina era ministrada me fez perder o interesse, pois era apenas leitura de slides com infimas explicações. Os trabalhos eram meio que você se vira para fazer', sem saber se está sendo feito pelo menos uma coisa no rumo certo (...).",

Quando indagado sobre o que mudaria (QA 4.3), o aluno citou a metodologia, propondo que contenha mais exemplos e exercícios de fixação. Com relação à QA 4.5, o estudante afirmou que sentiu as mesmas dificuldades, no entanto, ele esforçou-se mais para conseguir aprovação. Como sugestão sobre mudanças na disciplina (QA 4.6), o participante afirmou:

"Creio que uma explicação mais detalhada seria melhor do que apenas uma breve leitura de slides. Exercícios para fixação do assunto estudado seriam também muito interessantes, (...)."

\section{Discussão dos Resultados}

Os resultados obtidos nesta pesquisa permitiram identificar a opinião de estudantes de Ciência da Computação da Universidade Federal do Maranhão sobre as metodologias e as dificuldades de aprendizado considerando a disciplina introdutória de Engenharia de Software. Ao todo, 73 alunos de diferentes perfis responderam ao questionário, tornando possível traçar uma descrição de como é aplicado o conteúdo e as dificuldades que eles encontram em aprender com eficiência e qualidade. Algumas mudanças sugeridas pelos estudantes são de fácil implementação, como considerar uma abordagem voltada para prática, tanto nos exemplos quanto nos trabalhos.

É importante ajudar a comunidade acadêmica a se adequar às mudanças de paradigmas e às novas tecnologias que surgem quase que diariamente, tendo impacto na adaptação dos estudantes no mercado de trabalho e na qualidade de formação. Considerar a opinião dos alunos no processo de aprendizado pode ajudar no alcance de melhores índices de qualificação. Segundo Mizukami [1986], no ensino tradicional, a aprendizagem consiste em aquisição de informações e demonstrações transmitidas, e é a que propicia a formação de reações estereotipadas, de automatismos denominados hábitos, geralmente isolados uns dos outros e aplicáveis, quase sempre, somente às situações idênticas em que foram adquiridos. $\mathrm{O}$ aluno que adquiriu o hábito ou que "aprendeu" apresenta, com frequência, compreensão apenas parcial. Ignoram-se neste processo de ensino as diferenças individuais. Pelas respostas dos estudantes, nota-se que para Engenharia de Software essa abordagem não é a mais eficiente, e que o ensino com abordagem absolutamente teórica não corresponde às expectativas dos alunos para a disciplina. Com relação aos alunos que aprovaram de primeira, mostra-se uma 
insatisfação sobre a didática utilizada pelos docentes e a dificuldade de aplicar os conteúdos na prática.

\section{Considerações Finais}

Este artigo apresentou um estudo para identificar as dificuldades e as expectativas de estudantes de graduação sobre a ES, bem como as dificuldades enfrentadas no seu processo de ensino-aprendizagem. Foi aplicada uma pesquisa de opinião para extrair tais informações dos alunos em 5 diferentes perfis: (1) alunos que nunca cursaram a disciplina, (2) alunos que no momento de aplicação da pesquisa estavam cursando a disciplina pela primeira vez, (3) alunos que reprovaram e estavam cursando novamente, (4) alunos que já haviam cursado e obtiveram aprovação de primeira e (5) alunos que foram aprovados, mas tiveram que cursar a disciplina mais de uma vez. A partir das respostas obtidas, foram feitas análises quantitativas e qualitativas. Embora não houve alunos do perfil 3, tais análises permitiram identificar as expectativas dos alunos por uma disciplina voltada para a prática e com uso de materiais diversos. E entre as dificuldades, além de um conteúdo teórico predominante, a falta de atividades práticas também foi citada. Conteúdos extensos ou muito teóricos podem dificultar o ensino-aprendizagem, evidenciando tais necessidades.

Como trabalho futuro desta obra, pretende-se: (i) analisar todas as disciplinas que tenham relação com Engenharia de Software e estejam presentes na grade curricular do curso Ciência da Computação da Universidade Federal do Maranhão, (ii) melhorar a análise das respostas obtidas, continuando as etapas de análise sugeridas pelo método GT e (iii) ampliar o domínio de participantes para fora da universidade.

\section{Referências}

Andrade, R. M. C., Santos, I. S., Araújo, I. L., Aragão, B. S., and Si-ewerdt, F. (2017). Retrospective for the last 10 years of teaching software engineering in ufc's computer department. InProceedings of the 31st Brazilian Symposium on Software Engineering, pages 358-367. ACM.

Batista, E. d. O. (2017).Sistemas de informação. Editora Saraiva.

Carossi, D. F., Pedan, J. M., and de Almeida Teixeira Filho, J. G. (2017). Utilização da metodologia"grounded theory"na identificação de informações para compor um plano de dados abertos de instituições federais de ensino superior.iSys-Revista Brasileira de Sistemas de Informação, 10(2):171-192.

Costa, T. and Bublitz, F. (2013). Análise dos principais problemas que afetam alunos de programação: uma investigação empírica no estado da paraíba. In: CSBC 2013 XXXIII Congresso da Sociedade Brasileira de Computação.

Gil, A. C. (2008). Métodos e técnicas de pesquisa social. 6. ed. Editora Atlas S A.

Gonçalves, W. A. (2016). O método grounded theory: Um norte teórico segundo o estadoda-arte do último biênio.Revista Conbrad [ISSN 2525-6815] Qualis B5, 1(2):117-134.

Melo, L. B. (2013) “O humor como estratégia de ensino na disciplina de Análise e Projeto de Sistemas”. In: WEI - XXXIII Workshop sobre Educação em Computação, 2013. Maceió, AL, p. 466. 
Mizukami, M. D. G. N. (1986). Ensino: as abordagens do processo. São Paulo: Editora Pedagógica e Universitária.

Portela, C., Vasconcelos, A., and Oliveira, S. R. B. (2016). Frames: Uma proposta de framework para o ensino de tópicos da engenharia de software. In Brazilian Symposium on Computers in Education (Simpósio Brasileiro de Informática na Educação-SBIE), volume 27, page 1361.

Santos, R., Werner, C., Costa, H., Abílio, R., and Borges, H. (2012). Managing reusable learning objects and experience reports in eduse portal. In2012 IEEE 13th International Conference on Information Reuse \& Integration (IRI), pages 631-638. IEEE.

Soares, M. S. (2015). Uma experiência de ensino de Engenharia de Software orientada a trabalhos práticos. https://www.researchgate.net/publication/267788165_Uma_exp eriencia_de_ensino_de_Engenharia_de_Software_orientada_a_trabalhos_praticos.

Sommerville, I. (2011). Software engineering 9th edition.ISBN-10, 137035152.

Vilarim, G. and Nascimento, A. (2013). Engenharia de software e processos de produção: questões sobre quem produz e como se produz. In: CSBC 2013 XXXIII Congresso da Sociedade Brasileira de Computação.

Von Wangenheim, C. G., Kochanski, D., and Savi, R. (2009). Revisão sistemática sobre avaliação de jogos voltados para aprendizagem de engenharia de software no brasil. Proceedings of the FEES-Fórum de Educação em Engenharia de Software. 